\title{
A 20-year follow-up of a population sample (aged 25-34) including coal-miners and foundry workers in Staveley, Derbyshire
}

\author{
A L COCHRANE ${ }^{1}$ AND F MOORE 2
}

From Rhoose Farm House, ${ }^{1}$ Rhoose, S Glamorgan, and the MRC Epidemiology Unit, ${ }^{2}$ Cardiff, UK

ABSTRACT A 20-year follow-up of a population sample of men aged 25-34 has been completed in Staveley, Derbyshire. The sample was based on a private census, with brief industrial histories, that enabled four groups to be established-“"non-dusty," "pure coal-mining," "pure foundry," and "other and mixed." The similarity of the mortality rates of the non-dusty, coal-mining, and foundry groups is satisfactory, but there is, however, a surprisingly high mortality rate in the other and mixed group. We were unable to explain this on the basis of their industrial exposure, and only to a very limited extent by their smoking habits. We suggest that there is a small group of uncooperative men, overweight for their height and heavy smokers, who self-select themselves into jobs that are classified in a study such as this as other and mixed.

The original survey was carried out by the MRC's Pneumoconiosis Unit. ${ }^{1}$ A complete private census, together with brief industrial histories, was taken of men aged 25-34 and 55-64 living in Staveley, Derbyshire. This paper is concerned with the younger age-group.

On the basis of the industrial histories, the population was divided into four groups-" "nondusty," "pure coal-mining," "pure foundry," and "other and mixed." Different sampling fractions were applied to the four groups. The population was followed up nine years later. ${ }^{2}$

\section{Material and methods}

We are confident that the fate of all the 369 men examined in 1957 is known, with the certified causes of death, exactly 20 years (to the day) since they were examined. In addition the heights and weights, the industrial histories taken in 1957 and also at the time of the follow-up in 1966, and the smoking histories taken in 1957 were used in this analysis.

\section{Results}

Table 1 shows the mortality from all causes in the

This work was partly supported by a grant from the National Coal Board.

Received 17 July 1979

Accepted 2 October 1979
Table 1 Staveley men aged 25-34: mortality rates at exactly 20 years from initial examination

\begin{tabular}{lrcr}
\hline Occupation group & No & No dead & $\%$ \\
\hline Non-dusty & 114 & 4 & $3 \cdot 5$ \\
Pure coal-mining & 94 & 4 & $4 \cdot 3$ \\
Pure foundry & 91 & 4 & $4 \cdot 4$ \\
Other and mixed & 70 & 8 & $11 \cdot 4$ \\
All & 369 & 20 & $5 \cdot 4$ \\
\hline
\end{tabular}

four groups. The similarity of the mortality rates of the non-dusty, coal-mining, and foundry groups is satisfactory; however the high mortality rate in the other and mixed group would conventionally be regarded as statistically significant. This caused us some alarm as the other and mixed group had been viewed with suspicion, both at the time of the 1957 survey ${ }^{1}$ and at the time of the follow-up survey. ${ }^{2}$

Table 2 shows the mortalities from specific causes in the four groups according to the "B list" of the International Classification of Diseases (eighth revision). Because the increase in mortality is spread among several specific causes, the probability of the excess mortality being due to one industrial cause was rendered unlikely, but we thought we should look at the industrial histories more closely before abandoning it.

Table 3 summarises the predominant occupations and causes of death of the eight people who died in this group. This did not give us any clear-cut lead. We next tried the alternative approach of sub- 
Table 2 Staveley men aged 25-34: specific causes of death according to the " $B$ list" of the International Classification of Diseases (eighth revision)

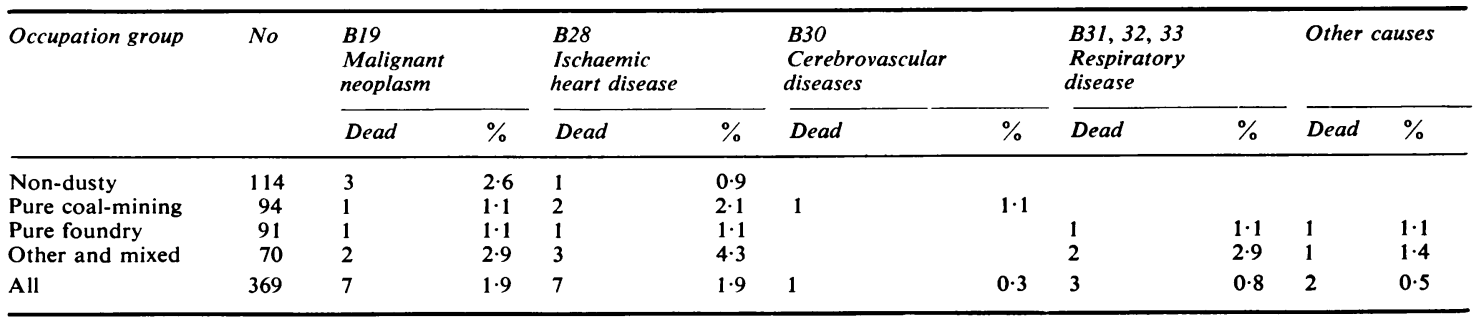

Table 3 Staveley "other and mixed" age 25-34: cause of death and main occupation of eight deaths

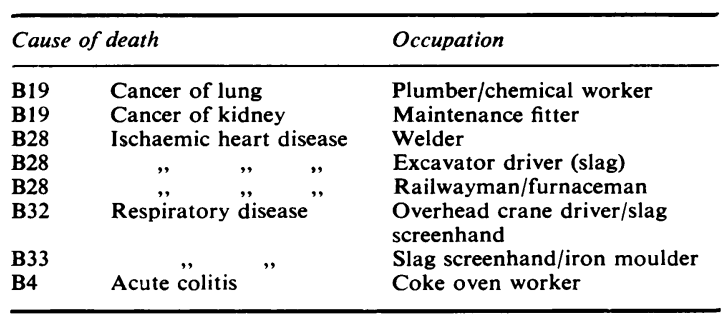

dividing the group by "predominant" occupation (an exercise that was neither easy nor very reproducible) (table 4). Here again there was no lead. We therefore looked at other characteristics of the four groups that might influence mortality. The obvious choice was smoking habits (table 5). The other and mixed are heavy smokers but their habits are comparable with those of the pure miners, so these cannot be held responsible for all their increased mortality.

Becoming suspicious that selection might play some part in this curious result, we reconstituted the complete cohort (table 6), and compared it with the same age-group in the 20-year follow-up study of the Rhondda Fach, ${ }^{3}$ which enabled us to compare the mortality rates with those of England and Wales as the standardised mortality ratio for Rhondda Fach non-miners aged 25-74 was 98.7.

Clearly the Staveley cohort (25-34) has a slightly lower mortality, from all causes, than the non-
Table 4 Staveley "other and mixed" age 25-34

\begin{tabular}{lllr}
\hline Subgroup & No & Dead & $\%$ \\
\hline Chemicals and coke ovens & 14 & 2 & $14 \cdot 3$ \\
Mining/foundry/chemicals mixed & 21 & 1 & $4 \cdot 8$ \\
Fitters/electricians, etc & 16 & 1 & $6 \cdot 3$ \\
Other dust exposure & 19 & $4^{*}$ & $21 \cdot 1$ \\
All & 70 & 8 & $11 \cdot 4$ \\
\hline
\end{tabular}

*Three of these considered to have "low" dust exposure.

miners in the Rhondda Fach. ${ }^{3}$ This suggests that this Staveley cohort as a whole is a reasonably healthy one, though it does not rule out the possibility that one small subgroup might have a high standardised mortality ratio.

At this stage we naturally examined the hypothesis that there was some curious correlation between the characteristic of staying in one job and a low mortality rate. To test this hypothesis we divided the other and mixed into those who had changed their job frequently, and into those who were less occupationally mobile. We did the division independently and produced similar results (table 7), which gave no support to our hypothesis.

Rather in desperation, we looked at other characteristics of this odd group. Table 8 gives the results of an analysis of the four groups by distribution and mortality by Quetelet's Index $\left(\frac{\mathrm{wt}}{\mathrm{ht}} 2\right)$ (which we have found of prognostic value in some unpublished 20-year follow-up studies in higher age

Table 5 Staveley men aged 25-34: smoking habits and mortality

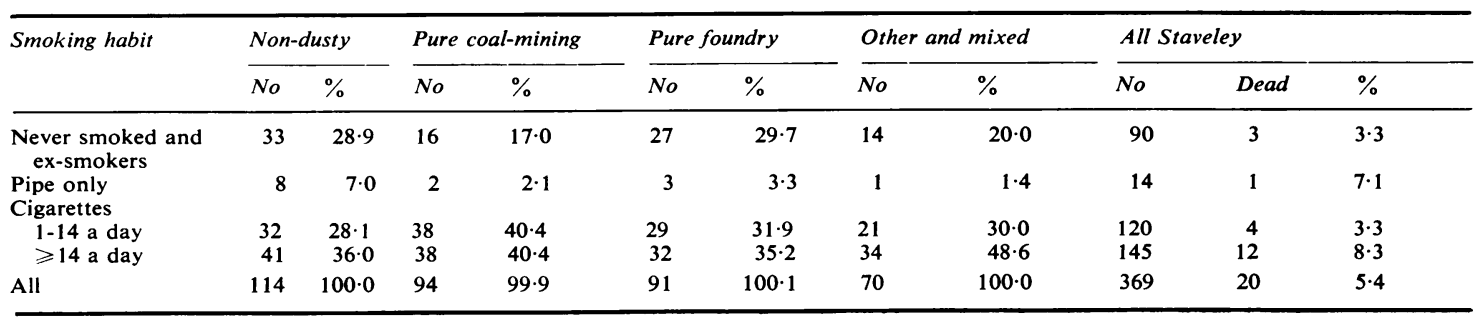


Table 6 Staveley men aged 25-34 compared with Rhondda Fach non-miners of the same age

\begin{tabular}{lcll}
\hline Area/group & No & Dead & $\%$ \\
\hline Rhondda Fach non-miners & 737 & 48 & $6 \cdot 5$ \\
Staveley "dusty"* & 636 & $41 \cdot 8$ & 6.6 \\
All Staveley* & 1040 & 56.0 & $5 \cdot 4$ \\
\hline
\end{tabular}

*For comparison with the Rhondda Fach group the original population is reconstructed according to the original sampling fractions.

Table 7 Staveley other and mixed group age 25-34: mortality according to occupation subgroups

\begin{tabular}{llll}
\hline Subgroup & No & Dead & $\%$ \\
\hline "Pure" other & 12 & 2 & $16 \cdot 7$ \\
Mixed & 58 & 6 & $10 \cdot 3$ \\
Both & 70 & 8 & $11 \cdot 4$ \\
Mixed only- & \multicolumn{1}{c}{ changes } & of occupation \\
Infrequent & 20 & 2 & $10 \cdot 0$ \\
Frequent & 38 & 4 & $10 \cdot 5$ \\
Both & 58 & 6 & $10 \cdot 3$ \\
\hline
\end{tabular}

groups). The distribution of body type in the other and mixed group is similar to that of the non-dusty group, but the case-fatality rate is much higher in the upper range in the other and mixed group.

We also looked at social class (table 9). We found it rather unsatisfactory for this particular study as according to the Classification of Occupations $1970^{4}$ all miners working underground must be classified as class III, and those on the surface as IV, except artisans. This makes the comparison between coalminers and other workers rather biased. Table 9 shows that there is, as expected, an overall relation- ship between mortality and social class; and that the distribution of social class in foundry workers, and in the other and mixed group on the one hand and the non-dusty on the other, is very different, but as there is no difference in the distribution of social class between the foundry workers and the other and mixed group it is unlikely the social class can explain the differences in mortality.

We finally looked at the order of being examined. This is a difficult type of investigation, as the order is inevitably related to the order in which they were visited. There were further snags. Thus there was some correlation between the areas in which people lived and their occupation, and there were also two decisions taken as regards priority in visiting. We agreed to give priority to the older age group and to delay visiting the miners for the first two days as they lived slightly further away. The visiting was done by three members of the MRC staff (one of whom was ALC). There was certainly no bias against visiting the other and mixed group which we believe was scattered throughout the community. Serial numbers were allocated in the order they came to the centre. Table 10 gives the percentage of each occupational group in the four sets of 200 numbers taken consecutively. Those in the last 200 were visited very frequently. Clearly the other and mixed group were, to say the least, uncooperative. An even odder result is shown in table 11 , which relates the order of being examined to mortality. None of the deaths in the other and mixed group occurred within two years of the survey.

Table 8 Quetelet index (excluding one pure foundry who died in first two years and one pure foundry where height and weight were not recorded)

\begin{tabular}{|c|c|c|c|c|c|c|c|c|c|c|c|c|c|c|c|c|}
\hline \multirow[t]{2}{*}{ Quetelet index } & \multicolumn{4}{|c|}{ Non-dusty } & \multicolumn{4}{|c|}{ Pure coal-mining } & \multicolumn{4}{|c|}{ Pure foundry } & \multicolumn{4}{|c|}{ Other and mixed } \\
\hline & No & $\%$ & Dead & $\%$ & No & $\%$ & Dead & $\%$ & No & $\%$ & Dead & $\%$ & No & $\%$ & Dead & $\%$ \\
\hline $\begin{array}{l}\text { Below 21.5 } \\
21 \cdot 5-24 \cdot 4 \\
\geqslant 24 \cdot 5\end{array}$ & $\begin{array}{l}35 \\
41 \\
38\end{array}$ & $\begin{array}{l}30 \cdot 7 \\
36 \cdot 0 \\
33 \cdot 3\end{array}$ & $\begin{array}{l}0 \\
1 \\
3\end{array}$ & $\begin{array}{l}-\overline{2 \cdot 4} \\
7: 9\end{array}$ & $\begin{array}{l}25 \\
44 \\
25\end{array}$ & $\begin{array}{l}26 \cdot 6 \\
46 \cdot 8 \\
26.6\end{array}$ & $\begin{array}{l}1 \\
2 \\
1\end{array}$ & $\begin{array}{l}4 \cdot 0 \\
4 \cdot 5 \\
4 \cdot 0\end{array}$ & $\begin{array}{l}40 \\
33 \\
16\end{array}$ & $\begin{array}{l}44 \cdot 9 \\
37 \cdot 1 \\
18 \cdot 0\end{array}$ & $\begin{array}{l}2 \\
1 \\
0\end{array}$ & $\begin{array}{l}5 \cdot 0 \\
3 \cdot 0 \\
-\end{array}$ & $\begin{array}{l}23 \\
24 \\
23\end{array}$ & $\begin{array}{l}32 \cdot 9 \\
34 \cdot 3 \\
32 \cdot 9\end{array}$ & $\begin{array}{l}1 \\
0 \\
7\end{array}$ & $\begin{array}{l}4 \cdot 3 \\
30 \cdot 4\end{array}$ \\
\hline All & 114 & $100 \cdot 0$ & 4 & $3 \cdot 5$ & 94 & $100 \cdot 0$ & 4 & $4 \cdot 3$ & 89 & $100 \cdot 0$ & 3 & $3 \cdot 4$ & 70 & $100 \cdot 1$ & 8 & $11 \cdot 4$ \\
\hline
\end{tabular}

Table 9 Staveley men aged 25-34: social class and mortality

\begin{tabular}{|c|c|c|c|c|c|c|c|c|c|c|c|}
\hline \multirow[t]{3}{*}{ Social class } & \multicolumn{8}{|c|}{ Occupation groups } & \multirow{2}{*}{\multicolumn{3}{|c|}{ All }} \\
\hline & \multicolumn{2}{|c|}{ Non-dusty } & \multicolumn{2}{|c|}{ Pure coal-mining } & \multicolumn{2}{|c|}{ Pure foundry } & \multicolumn{2}{|c|}{ Other and mixed } & & & \\
\hline & No & $\%$ & No & $\%$ & No & $\%$ & No & $\%$ & No & Dead & $\%$ \\
\hline I & 3) & & 2) & & -7 & & -7 & & 5 & - & - \\
\hline II & $9\}$ & $28 \cdot 1$ & $3\}$ & 6.4 & $1\}$ & $2 \cdot 2$ & $-\}$ & 1.4 & 13 & - & - \\
\hline IIIN & $20\}$ & & $1\}$ & & if & & $1\}$ & & 23 & 1 & $4 \cdot 3$ \\
\hline IIIM & 67 & 58.8 & 75 & $79 \cdot 8$ & 60 & 65.9 & 45 & $64 \cdot 3$ & 247 & 11 & 4.5 \\
\hline IV & 12\} & 13.2 & 12\} & 13.8 & 21) & 31.0 & 16? & 34.3 & 61 & 6 & 9.8 \\
\hline $\mathrm{v}$ & $3\}$ & $13 \cdot 2$ & $1\}$ & 13.8 & $8\}$ & 31.9 & $8\}$ & $34 \cdot 3$ & 20 & 2 & $10 \cdot 0$ \\
\hline All & 114 & $100 \cdot 1$ & 94 & $100 \cdot 0$ & 91 & $100 \cdot 0$ & 70 & $100 \cdot 0$ & 369 & 20 & $5 \cdot 4$ \\
\hline
\end{tabular}


Table 10 Staveley men aged 25-34: order of coming to be examined

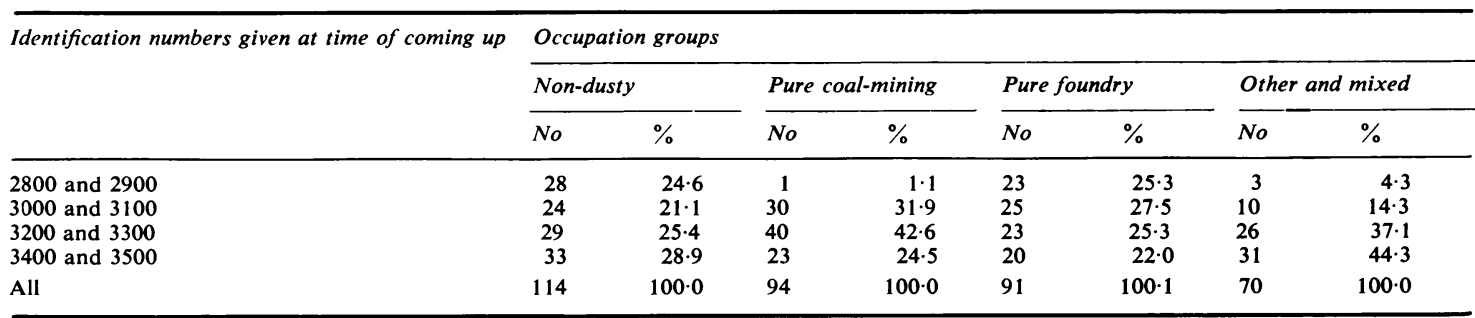

Table 11 Staveley men aged 25-34: order of being examined and mortality

\begin{tabular}{|c|c|c|c|c|c|c|}
\hline $\begin{array}{l}\text { Identification numbers given at time } \\
\text { of coming up }\end{array}$ & \multicolumn{3}{|c|}{$\begin{array}{l}\text { Non-dusty } \\
\text { Pure coal-mining } \\
\text { Pure foundry }\end{array}$} & \multicolumn{3}{|c|}{ Other and mixed } \\
\hline $\begin{array}{l}2800 \text { and } 2900 \\
3000 \text { and } 3100 \\
3200 \text { and } 3300 \\
3400 \text { and } 3500\end{array}$ & $\begin{array}{l}52 \\
79 \\
92 \\
76\end{array}$ & $\begin{array}{l}3 \\
1 \\
3 \\
5\end{array}$ & $\begin{array}{l}5 \cdot 8 \\
1 \cdot 3 \\
3 \cdot 3 \\
6 \cdot 6\end{array}$ & $\begin{array}{r}3 \\
10 \\
26 \\
31\end{array}$ & $\begin{array}{l}0 \\
0 \\
2 \\
6\end{array}$ & $\begin{array}{l}- \\
\overline{7} \cdot 7 \\
19 \cdot 4\end{array}$ \\
\hline All & 299 & 12 & $4 \cdot 0$ & 70 & 8 & $11 \cdot 4$ \\
\hline
\end{tabular}

Mortality in this group, but not in the others, appears to be associated with body-type and "uncooperativeness," and possibly smoking habit.

We examined the possibility of "potentiation" between the various pairs of these three factors by means of " $2 \times 2$ " tables. We could find no such evidence, but owing to the small numbers of deaths we were unable to exclude such a possibility.

We can only conclude that there is a small group of overweight, uncooperative men who smoke more than average, who have a raised mortality, and who select themselves by their uncooperativeness into the other and mixed group. They would appear to be a menace to themselves. They are certainly a menace to epidemiologists.

\section{References}

${ }^{1}$ Higgins ITT, Cochrane AL, Gilson JC, Wood CH. Population studies of chronic respiratory disease. A comparison of miners, foundry workers, and others in Staveley, Derbyshire. Br J Ind Med 1959;16:255-68.

${ }^{2}$ Higgins ITT, Gilson JC, Ferris BG Jr, Waters WE, Campbell H, Higgins MW. Environmental epidemiology. IV Chronic respiratory disease in an industrial town; a nine-year follow-up study. Preliminary report. $\mathrm{Am} \mathrm{J}$ Public Health 1968;58:1667-76.

${ }^{3}$ Cochrane AL, Haley TJL. Moore F, Hole D. The mortality of men in the Rhondda Fach. Br J Ind Med 1979;36: 15-22.

${ }^{4}$ Office of Population Censuses and Surveys. Classification of Occupations 1970. London: HMSO, 1970. 